\title{
Electrobioremediation of Patagonian Soils Contaminated with Hydrocarbons
}

\author{
G.N. Pucci, ${ }^{a,}{ }^{*}$ A.J. Acuña, ${ }^{a}$ L.Y. Wick ${ }^{b}$ and O.H. Pucci ${ }^{a}$ \\ ${ }^{a}$ CEIMA, Universidad Nacional de la Patagonia San Juan Bosco Apartado postal 9000, 4km ruta \\ provincial $N^{\circ} 1$, Comodoro Rivadavia, Argentina \\ ${ }^{b}$ UFZ, Centro de Investigaciones Ambientales Leipzig-Halle. Departamento de Microbiología Ambiental. \\ Permoserstrasse 15, Leipzig, Alemania
}

Received 27 July 2012; accepted 31 October 2012

\begin{abstract}
The electrokinetic technique is used to remediate hydrocarbon-contaminated soil. The aim of this paper is to evaluate the feasibility of using this technology to remediate oilcontaminated soils in the Gulf of San Jorge. The soils used in this experiment were unsaturated soils contaminated by oil field operations being carried out in the area and previously remediated by landfarming. A potential difference of $0.5 \mathrm{~V} \mathrm{~cm}-1$ was applied to the electroremediation cells for 120 days; bridges of phosphate salt were used for the cells. Total hydrocarbons decreased from $4.22 \%$ to $3 \%$, modifying the percentages of aliphatic, aromatic and polar hydrocarbons. The $\mathrm{pH}$ changed from 7.96 to 8.6 and 7.1 in the cathode and anode, respectively. The final $\mathrm{pH}$ values were compatible with the degrading bacterial community, whose colony-forming numbers did not present any alteration. On the cathode, there was an increase in the percentage of Gram-positive bacteria. Most of the species isolated were identified as Microbacterium luteus.
\end{abstract}

Keywords: electrokinectic, TPH, bacteria, unsaturated soil.

\section{Introducción}

La electrorremediación es una tecnología utilizada para restaurar suelos contaminados por la aplicación de un campo eléctrico a partir de corriente directa [1]. Al aplicar corriente directa en un suelo, los contaminantes existentes pueden ser removidos debido a que se producen, en su matriz, movimientos de electromigración, electroósmosis y electroforesis [2]. Esto produce un aumento de la biodisponibilidad de compuestos orgánicos, lo que lleva a un aumento en la biodegradación de los mismos [3]. Existen diferentes factores que influyen en el proceso. Uno de ellos es el $\mathrm{pH}$, se produce una acidificación en la región del ánodo y una alcalinización en la del cátodo. Otro factor es el contenido de agua

\footnotetext{
* Corresponding author. E-mail: granapu@unpta.edu.ar
} 
del suelo contaminado, éste debe estar en un porcentaje óptimo para el pasaje de corriente sin llegar a producir saturación, ya que podría inhibir los procesos de biorremediación a cargo de los microorganismos [4].

Desde hace un siglo, en la región del Golfo San Jorge se realizan actividades relacionadas con la extracción de hidrocarburos. Durante este tiempo se fue modificando la legislación ambiental, haciéndose más exigente y fijando límites más estrictos con respecto a la concentración de hidrocarburos presente en suelos contaminados. Esto implicó el saneamiento de suelos con contaminaciones antiguas de hidrocarburos poco biodisponibles. Actualmente en la región se aplican, para resolver este tipo de problemas, técnicas de biorremediación convencionales asistidas con nutrientes por los métodos de landfarming o biopilas. Éstas dan excelentes resultados con hidrocarburos alifáticos, y en la mayoría de los casos, con hidrocarburos aromáticos y polares [5]. Uno de los inconvenientes de estos hidrocarburos, aromáticos y polares, es su biodisponibilidad. La electrorremediación aumenta la biodisponibilidad de este tipo de compuestos favoreciendo la posterior biodegradación de los mismos [3]. Esta técnica se ha aplicado exitosamente en suelos saturados contaminados con un hidrocarburo puro, disminuyendo esta eficiencia cuando se trabaja con suelos que poseen una contaminación antigua.

La electrobiorremediación combina la aplicación de corriente eléctrica directa con técnicas de biorremediación asistida con nutrientes, aireación y agua. Se busca estimular la biodegradación de contaminantes orgánicos al introducir nutrientes para las bacterias dentro del suelo, de manera que el campo eléctrico acelere la desorción de los contaminantes desde las partículas de suelo, incrementando su biodisponibilidad para que los microorganismos los incorporen a su metabolismo, o bien sean estabilizados como resultado de reacciones químicas entre el contaminante y productos metabólicos como el sulfuro y los metales divalentes [6]. Esta modificación ha sido probada con moléculas orgánicas sintéticas como TNT, BPC y pesticidas [7].

El objetivo de este trabajo es conocer la factibilidad de uso de esta tecnología para suelos no saturados contaminados con hidrocarburos de la región del Golfo San Jorge.

\section{Materiales y métodos \\ Toma de muestra}

Se trabajó con un suelo proveniente de un sistema de biorremediación por el método de landfarming situado al norte de la ciudad de Comodoro Rivadavia, en la región del Golfo San Jorge. Se tomaron 20 muestras del sitio a una profundidad comprendida entre 10 y $30 \mathrm{~cm}$ que se mezclaron y redujeron por cuartetos hasta un peso de $15 \mathrm{~kg}$ sobre la que se realizaron los estudios. El suelo posee un $\mathrm{pH}$ de 7.4 , humedad de $1.88 \%$, densidad aparente de 1.19 g.mL $\mathrm{mL}^{-1}$, densidad real de $1.56 \mathrm{~g} . \mathrm{mL}^{-1}, \zeta-25.30$, hidrocarburos totales $4.22 \%$. 


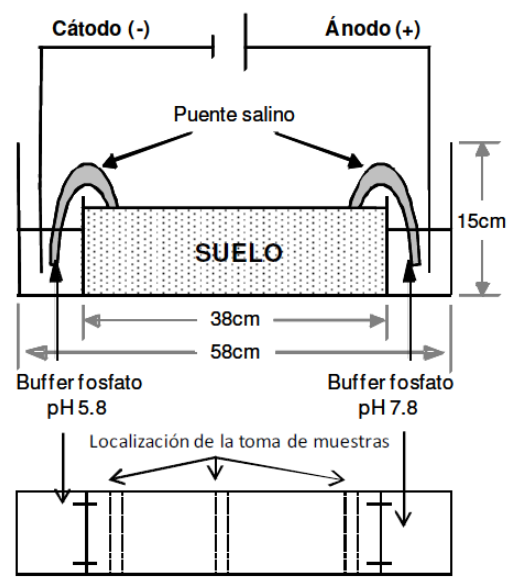

Figura 1. Esquema del sistema utilizado para la experiencia de electrobiorremediación y localización de la toma de muestras durante el ensayo.

\section{Experiencia de electrobiorremediación}

Para los ensayos se utilizaron tres cubas de vidrio de $58 \mathrm{~cm}$ de largo, $15 \mathrm{~cm}$ de alto y $15 \mathrm{~cm}$ de ancho. El interior de estas estuvo dividido por vidrio en tres compartimientos, dos de ellos de $10 \mathrm{~cm}$ de largo, $15 \mathrm{~cm}$ de alto y $15 \mathrm{~cm}$ de ancho, ubicados uno a cada extremo de las cubas en donde se colocaron las soluciones buffer. El tercer compartimiento fue el central, de $38 \mathrm{~cm}$ de largo, 15 $\mathrm{cm}$ de alto y $15 \mathrm{~cm}$ de ancho, donde se colocó el suelo (Fig. 1). La experiencia de electrobiorremediación consistió en la colocación de buffer fosfato de potasio 1 M en los compartimientos de los extremos. El buffer a pH 5.8 se colocó en el compartimiento correspondiente al cátodo y el de $\mathrm{pH} 7.8$ en el correspondiente al ánodo [8]. En estas soluciones fueron sumergidos los electrodos de platino y el paso de corriente a través del suelo se logró por la unión de las soluciones buffer con el suelo, utilizando puentes salinos de buffer fosfato. Para los ensayos se utilizaron $4 \mathrm{~kg}$ de suelo fertilizado con nutrientes para corregir su relación C:N:P. La humedad del suelo utilizado fue de 12 a $15 \%$ [2,9] y el voltaje aplicado fue de $0.5 \mathrm{~V} . \mathrm{cm}^{-1}$ [10]. Como control, se utilizaron dos sistemas sin aplicación de corriente. Uno con iguales características respecto al contenido de nutrientes y humedad $(\mathrm{NH})$, y otro solo con respecto a la humedad $(\mathrm{H})$. $\mathrm{Al}$ inicio y al final de la experiencia se realizó un análisis físico, químico, bacteriológico y aislamiento e identificación de cepas bacterianas. Todos los sistemas fueron incubados a 24 ${ }^{\circ} \mathrm{C}$ durante 120 días.

\section{Análisis físico y químico}

Las determinaciones y cuantificación de $\mathrm{pH}$, cationes y aniones se realizaron sobre un extracto de suelo 1:2.5 en agua destilada. La determinación de $\mathrm{pH}$ fue realizada con electrodo de vidrio. El contenido de amonio como azul de indofenol y el de fosfato con azul de molibdeno. El nitrito se determinó con ácido sulfanílico y 1-naftilamina y el nitrato con brucina en presencia de ácido sulfúrico [11]. Las determinaciones de temperatura y humedad por secado a 105 ${ }^{\circ} \mathrm{C}$ se realizaron según lo propuesto por García Trejo [12]. El contenido de hidrocarburos totales (HT) se determinó sobre $50 \mathrm{~g}$ de suelo mediante extracción en un equipo Soxhlet durante $24 \mathrm{~h}$ utilizando tricloroetano como solvente de 
extracción. Los hidrocarburos extraídos fueron cuantificados por diferencia de pesada [5]. Las fracciones de hidrocarburos alifáticos y aromáticos de los HT obtenidos fueron separadas por cromatografía en columna de silicagel a partir de $0.3 \mathrm{~g}$ de residuo. Como solventes de elución se utilizaron $250 \mathrm{~mL}$ de hexano y $150 \mathrm{~mL}$ de benceno para los hidrocarburos alifáticos y aromáticos, respectivamente. Las fracciones obtenidas se cuantificaron por diferencia de pesada [5]. La humedad de las cuba se siguió semanalmente manteniendo los valores entre $12-15 \%$ durante toda la experiencia.

\section{Enumeración de microorganismos}

El número de microorganismos fue determinado por la técnica de conteo en placa. Se utilizó una suspensión de $10 \mathrm{~g}$ de suelo en $90 \mathrm{~mL}$ de solución fisiológica estéril que se agitó 30 minutos a 150 r.p.m. Para bacterias heterótrofas se utilizó el medio R2A [13] (extracto de levadura $0.5 \mathrm{~g}$, peptona ácida de caseína $0.5 \mathrm{~g}$, casamino ácido $0.5 \mathrm{~g}$, glucosa $0.5 \mathrm{~g}$, almidón $0.5 \mathrm{~g}$, acetato de sodio $0.5 \mathrm{~g}$, fosfato ácido di potásico $0.3 \mathrm{~g}$, sulfato de magnesio decahidratado 5 $\mathrm{g}$, sulfato de sodio $36.6 \mathrm{~g}$, cloruro de sodio $0.99 \mathrm{~g}$, cloruro de potasio $7.51 \mathrm{~g}$, cloruro de magnesio $1.42 \mathrm{~g}$, bicarbonato de sodio $1.008 \mathrm{~g}$, agar-agar $14 \mathrm{~g}$, agua destilada $1000 \mathrm{~mL}, \mathrm{pH}$ 7.2). Para bacterias degradadoras de hidrocarburos (BDH) se utilizó un medio mineral (solución I: cloruro de calcio $0.235 \mathrm{~g}$, nitrato de potasio $0.427 \mathrm{~g}$, sulfato de amonio $5 \mathrm{~g}$, cloruro de magnesio hexahidratado $1 \mathrm{~g}$, bicarbonato de potasio $1.2 \mathrm{~g}$. Solución II: fosfato ácido di sódico dihidratado 0.5 g, fosfato monopotásico 0.5 g. Solución III: EDTA-Na 800 g, cloruro ferroso 300 $\mathrm{g}$, cloruro de calcio hexahidratado $4 \mathrm{~g}$, cloruro de manganeso tetrahidratado $10 \mathrm{~g}$, sulfato cúprico $1 \mathrm{~g}$, permanganato de potasio dihidratado $3 \mathrm{~g}$, cloruro de zinc $2 \mathrm{~g}$, cloruro de litio $0.5 \mathrm{~g}$ ) al cual se le agregó $30 \mu \mathrm{L}$ de una mezcla de petróleo y gasoil 1:1 por diseminación en superficie que se denominó MBM-PGO [5].

\section{Aislamiento e identificación de cepas bacterianas}

A partir de las placas de MBM-PGO utilizadas para conteo de bacterias, se aislaron e identificaron 90 cepas por metil ésteres de ácidos grasos (FAMEs) según el método Sherlock MIDI versión 6.0. La extracción de ácidos grasos de membrana se realizó sobre $40 \mathrm{mg}$ de masa celular comenzando con una saponificación con alcohol metílico, hidróxido de sodio y agua (150 mL: $45 \mathrm{~g}$ : $150 \mathrm{~mL}$ ). Posteriormente se realizó una metilación con ácido clorhídrico $6 \mathrm{~N}$ y alcohol metílico (325 mL: $275 \mathrm{~mL}$ ), seguido de una extracción con $\mathrm{n}$-hexano y metil terbutil éter (1:1). Finalmente se realizó un lavado con hidróxido de sodio y agua (10.8 g en $900 \mathrm{~mL}$ ) de acuerdo a lo propuesto por el sistema de identificación (MIDI Newark, Del., USA).

Los ácidos grasos obtenidos se determinaron como metil ésteres por cromatografía gaseosa. Para tal fin se utilizó una columna capilar Ultra 2 de $25 \mathrm{~m}$ de longitud y $0.2 \mathrm{~mm}$ de diámetro. El análisis se llevó a cabo con un cromatógrafo HP 6890 series II GC (inyección splitless, presión inicial 10 psi, programa de temperatura: $170-288{ }^{\circ} \mathrm{C}$ a $28{ }^{\circ} \mathrm{C} \cdot \mathrm{min}^{-1}, 288-310{ }^{\circ} \mathrm{C}$ a $60{ }^{\circ} \mathrm{C} \cdot \mathrm{min}^{-1}$, 1.5 min de permanencia a $310{ }^{\circ} \mathrm{C}$, detector por ionización de llama). La integración de los pico se efectuó mediante el programa HP 10.01 Chem Station. 
Los ácidos grasos fueron identificados utilizando el sistema Sherlock (versión 6.0) con el estándar Agilent "Calibration standards kit for the microbial identification system”. La composición en ácidos grasos fue calculada como porcentaje del área de pico (MIDI).

\section{Análisis de resultados}

Los valores de hidrocarburos y recuentos bacterianos se analizaron por análisis de la varianza (ANOVA) mediante el programa BIOM (Applied Biostastics INc 3 Heritage Setauket NY 117II USA). Para el estudio de la comunidad bacteriana se realizó un análisis de componentes principales utilizando el programa PAST.

\section{Resultados y discusión}

La aplicación de corriente directa a un suelo, puede producir cambios en su granulometría, contenido de materia orgánica, conductividad eléctrica y cantidad de sales solubles, disminuyendo su contenido en sales inorgánicas como nitrato, fosfato y sulfato, empobreciendo de esta manera el suelo [1]. También produce modificación de su $\mathrm{pH}$, con disminución de $\mathrm{pH}$ en la región del ánodo y con aumento en la del cátodo. El campo eléctrico aplicado al suelo estudiado, indujo migración de nutrientes (Tabla 1). Esto modificó la biodisponibilidad de fosfatos, ya que aumentó su concentración, estando de acuerdo con los resultados encontrados por Xuejun et al. [14]. Se observó que el fosfato se mantuvo en mayor concentración en la región del cátodo, posiblemente por su liberación desde el puente salino utilizado. Gootaek et al. [15] recomienda la utilización de trietilfosfato como fertilizante en este tipo de sistemas, ya que este compuesto no es captado por el caolín presente en el suelo y así, se mantiene la concentración de fosfato constante, logrando mejores resultados en el proceso de biodegradación de hidrocarburos. Otro problema que presenta el agregado de fosfato inorgánico en suelos, es que en presencia de calcio, tiende a formar sales insolubles provocando su precipitación y haciéndolo poco biodisponible para los microorganismos. En los sistemas de electrobiorremediación, el ión nitrato posee una alta movilidad relativa [16], observándose que en presencia de un campo eléctrico, su desplazamiento es en dirección al ánodo (Fig. 2). El aumento de la concentración de nitrato observado en la región del cátodo y del ánodo en el sistema sometido a un campo eléctrico, y del suelo del sistema NH, también pudo deberse a la presencia de bacterias nitrificantes, que son frecuentemente observadas en los suelos de la región [11].

La electroósmosis se encuentra siempre en función del grado de saturación del suelo, por ello, es un factor importante en los sistemas de electrobiorremediación. La distribución no homogénea de la humedad del suelo, se debe a que el agua se mueve en dirección de uno de los electrodos, el cátodo, aumentando la humedad del suelo cercano a éste, la misma se mantuvo durante toda la experiencia dando el valor más alto de $16.5 \%$, y disminuyendo en el suelo cercano al ánodo, en el cual fue incorporada una cantidad variable de agua después del dosaje de la humedad para mantener el valor. Esta disminución se encuentra asociada al desarrollo de poros de presión negativa, a variación de $\mathrm{pH}$ y de la fuerza del 
campo eléctrico, lo cual resulta en una tasa de flujo electroosmótico irregular [1, $2,17]$.

Tabla 1. Valores de $\mathrm{pH}$, hidrocarburos totales del petróleo extraídos por soxhlet y fraccionamiento del petróleo en hidrocarburos alifáticos, y aromáticos por columna de silicagel, valores de los recuentos bacterias totales (R2A) y de bacterias degradadoras de petróleo (MBM-PGO) de los distintos sitios de la cuba con electricidad (ánodo, centro y cátodo) de las cubas control sin electricidad, una con humedad y nutrientes $(\mathrm{NH})$ y otra con humedad solamente $(\mathrm{H})$, también se encuentra el valor inicial de la muestra de suelo.

\begin{tabular}{|c|c|c|c|c|c|c|}
\hline & Inicial & Ánodo & Centro & Cátodo & $\mathrm{NH}$ & $\overline{\mathrm{H}}$ \\
\hline $\mathrm{pH}$ & 7.96 & 7.1 & 8.1 & 8.6 & 8 & 8.02 \\
\hline $\mathrm{HT}^{\mathrm{b}}$ & 4.22 & 2.96 & 3.11 & 3.06 & 3.11 & 3.62 \\
\hline H. alifáticos ${ }^{\mathrm{a}}$ & 22 & 7.99 & 10.26 & 9.67 & 10.79 & 14.26 \\
\hline $\begin{array}{l}\text { H. aromáticos }{ }^{\mathrm{a}} \\
\mathrm{R} 2 \mathrm{~A}^{\mathrm{c}}\end{array}$ & $\begin{array}{c}13 \\
2.6 \times 10^{8}\end{array}$ & $\begin{array}{c}7.76 \\
8.0 \times 10^{7}\end{array}$ & $\begin{array}{c}6.84 \\
7.0 \times 10^{7}\end{array}$ & $\begin{array}{c}12,15 \\
5.0 \times 10^{7}\end{array}$ & $\begin{array}{c}9.42 \\
4.4 \times 10^{7}\end{array}$ & $\begin{array}{c}9.96 \\
8.9 \times 10^{7}\end{array}$ \\
\hline MBM-PGO ${ }^{c}$ & $1.1 \times 10^{8}$ & $8.5 \times 10^{7}$ & $9.4 \times 10^{7}$ & $5.8 \times 10^{7}$ & $4.4 \times 10^{6}$ & $1.3 \times 10^{7}$ \\
\hline
\end{tabular}

$\mathrm{NH}$ : nutrientes y humedad, $\mathrm{H}$ : humedad. a: expresado en $\mathrm{mg} \cdot \mathrm{kg}^{-1}$, b: expresado en \% y c: expresado en UFC. $\mathrm{g}^{-1}$.
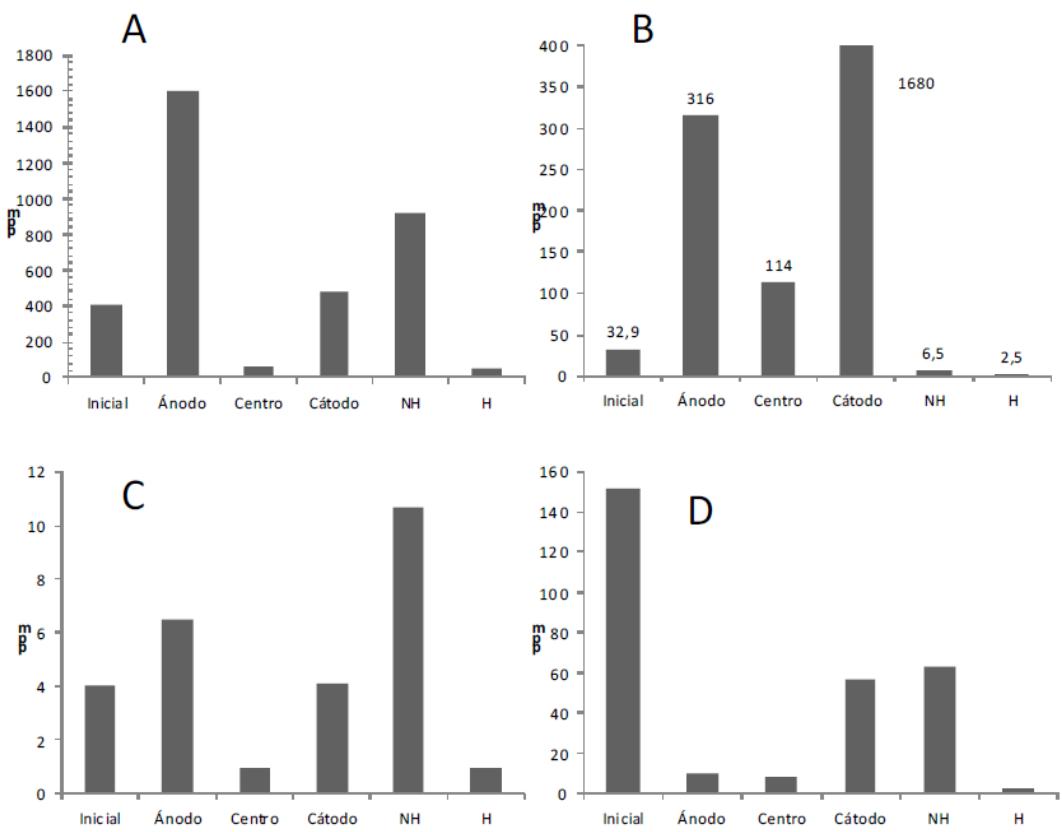

Figura 2. Valores de los iones, nitrato, fosfato, nitrito y amonio en los lugares de muestreo de las cubas con electricidad (ánodo, centro y cátodo) de las cubas controles que o poseían electricidad, la cuba con humedad y nutrientes $(\mathrm{NH})$ y la cuba con solo humedad $(\mathrm{H})$. Las figuras A, B, C y D corresponden a ppm del ión nitrato, fosfato, nitrito y amonio respectivamente. $\mathrm{NH}$ : nutrientes y humedad, $\mathrm{H}$ : humedad.

La aplicación de electrobiorremediación en suelos saturados, tiene el problema que, la circulación del agua a través del mismo, remueve hidrocarburos, generando un volumen de líquido contaminado que posteriormente debe ser tratado. Una de las ventajas observadas al trabajar con suelos no saturados, es que no se generan lixiviados en el sistema. Por otro lado, el mantenimiento de la 
humedad en sistemas no saturados, conlleva a un trabajo de seguimiento semanal para mantenerla entre 12 y $15 \%$, ya que, valores de humedad inferiores en el suelo, implican un aumento de la diferencia de potencial que debe ser aplicada a los electrodos para mantener un voltaje constante en el suelo, representando un mayor gasto de energía y un menor rendimiento del sistema. La disminución de humedad en el suelo de los sistemas, también pudo deberse a evaporación por calentamiento de los mismos o al desarrollo de reacciones químicas exotérmicas por aplicación de corriente directa [18]. La temperatura del suelo sometido a electrobiorremediación se mantuvo en $24.3 \pm 1{ }^{\circ} \mathrm{C}$ durante todo el ensayo, con una diferencia de $0.4{ }^{\circ} \mathrm{C}$ entre la región del ánodo y la del cátodo, y una temperatura ambiental de $24 \pm 2{ }^{\circ} \mathrm{C}$. Esto demuestra que los cambios observados en la humedad fueron, principalmente, debido a la presencia de un flujo electroosmótico provocado por el campo eléctrico aplicado, similar a lo observado por Schmidt et al. [19] al trabajar con un voltaje de $0.3 \mathrm{~V} . \mathrm{cm}^{-1}$.

Los hidrocarburos presentes en el suelo utilizado poseían una degradación previa ya que la muestra fue tomada de un sistema de tratamiento por el método de landfarming de varios años de desarrollo. La aplicación de electrobiorremediación aumentó la degradación de los hidrocarburos presentes caracterizados por una marcada recalcitrancia al no ser biodegradados en el tiempo en que se desarrolló el tratamiento de landfarming.

Se observó una disminución de hidrocarburos totales y un cambio en los porcentajes relativos de sus diferentes fracciones. En el sistema H, se observó la menor disminución de hidrocarburos totales, lo que podría estar asociado a una baja biodisponibilidad de los hidrocarburos presentes [10].

Los ensayos de cromatografía en silicagel mostraron modificaciones en los gramos de hidrocarburo contaminante (Tabla 1). La fracción de hidrocarburos alifáticos presentó una disminución en todos los tratamientos. En el sistema de electrobiorremediación, en la región del ánodo se observó una biodegradación de hidrocarburos alifáticos. Los hidrocarburos aromáticos presentaron mayor biodegradación en el centro de la cuba y un desplazamiento en dirección al flujo electroosmótico.

La utilización de puentes salinos y de un voltaje de $0.5 \mathrm{~V} . \mathrm{cm}^{-1}$ mantuvo el $\mathrm{pH}$ del suelo en valores óptimos para el desarrollo bacteriano, dejando de ser el pH un problema para la biodegradación de hidrocarburos durante los 120 días en que se desarrolló la experiencia. El mantenimiento del pH en valores aptos para los microorganismos produjo que su número no se modificara, ya que la diferencia de un log es el error que se le pude atribuir al método. El cambio de $\mathrm{pH}$ en los suelos, genera una carga en la membrana bacteriana que es responsable de la migración de los microorganismos hacia uno de los electrodos, dependiendo del valor de $\mathrm{pH}$ [20]. A pH 7 o mayor, se genera una carga negativa que conlleva a una migración de los microorganismos hacia el ánodo [21], si bien la velocidad en medios acuosos es rápida, $5 \mathrm{~cm} \cdot \mathrm{h}^{-1}$, en suelos este valor cae a $5 \mathrm{~cm}$ cada $6 \mathrm{~h}$. Cuando el $\mathrm{pH}$ es de 5.5 o menor, la carga de la membrana se hace positiva y esto conlleva a un cambio en la dirección de migración hacia el cátodo. La complejidad de las cargas superficiales que poseen las membranas bacterianas, hace difícil predecir el comportamiento de las mismas con los parámetros 
biofísicos [22]. La composición de los polímeros de los microorganismos contiene grupos carboxilo, sulfato, fosfato o amino, por lo que poseen grupos ácidos y básicos dando como resultado una superficie anfotérica que posee carga negativa a $\mathrm{pH}$ alto y positiva a $\mathrm{pH}$ bajo.

Durantes las últimas décadas, se realizaron diversos trabajos demostrando la factibilidad de movimiento de las bacterias en suelos arcillosos y en medios líquidos [10, 21]. Da Rocha et al. [23] trabajó con arcillas y esporas bacterianas, demostró que la electroforesis es el fenómeno responsable de la migración de esporas de Bacillus, permitiendo un bioaumento de bacterias autóctonas. El suelo cercano al cátodo del sistema sometido a electrobiorremediación, presentó un predominio de Microccus luteus, microorganismo que posee un alto valor de movilidad electroforética [22]. Este microorganismo se observó en menor cantidad en el centro del sistema sometido a electrobiorremediación y en el suelo de los sistemas $\mathrm{NH}$ y $\mathrm{H}$, utilizados como control. En la región del ánodo se observó una diversidad bacteriana diferente, sin un marcado predominio de un microorganismo específico. Sin embargo, en esta región del sistema de electrobiorremediación, se aisló al género Arthrobacter, coincidiendo con 1o observado por Lear et al. [24]. Los microorganismos Gram negativos se observaron en mayor porcentaje en la región del ánodo, mientras que los Gram positivos se observaron en mayor porcentaje en la región central y en la del cátodo, como así también en los controles NH y H. La región central del sistema sometido al campo eléctrico, es donde la humedad se mantuvo sin variaciones importantes y los nutrientes se observaron en baja concentración, situación que la asemeja más a las condiciones experimentadas en el sistema H (Fig. 3).

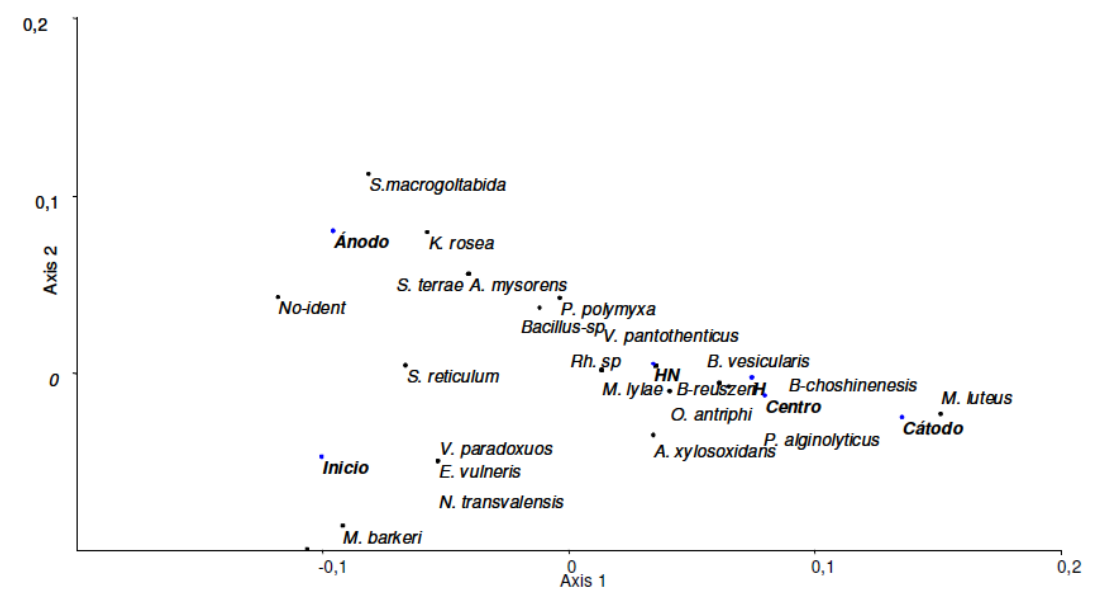

Figura 3. Análisis de componentes principales de las cepas identificadas.

A-xylosoxidans: Achromobacter xylosoxidans denitrificans, A-mysorens: Arthrobacter mysorens, B-choshinenesis: Brevibacillus choshinenesis, B-reuszeri: Brevibacillus reuszeri

B-vesicularis: Brevundimonas vesicularis, E-vulneris: Escherichia vulneris, M-barkeri: Microbacterium barkeri, M-luteus: Microccus luteus, M-lylae: Microccus lylae, No-ident: No identificada, $N$-transvalensis: Nocardia transvalensis, $O$-antriphi: Ochrobactrum antriphi, $P$ alginolyticus: Paenibacillus alginolyticus, P-polymyxa: Paenibacillus polymyxa, Rh-sp: Rhodococcus sp, S-macrogoltabida: Sphingopyxis macrogoltabida, S-maltophilia: Stenotrophomonas maltophilia, S-reticulum: Streproverticillium reticulum, V-paradoxuos: Variovorax paradoxuos, V-pantothenticus: Virgibacillus pantothenticus, S-terrae: Sphingomonas térrea, K-rosea: Kocuria rosea, Bacillus-sp: Bacillus sp. 


\section{Conclusiones}

La electrobiorremediación es un método aplicable a suelos contaminados con hidrocarburos que ya poseen una biodegradación previa por métodos biológicos convencionales. El uso de puentes salinos de buffer fosfato mantuvo el $\mathrm{pH}$ del suelo en valores compatibles con la viabilidad de los microorganismos, también mantuvo valores aceptables de nutrientes favoreciendo la biodegradación de los hidrocarburos presentes. Por los costos que poseen este tipo de sistemas, se recomendaría la aplicación de esta tecnología en suelos patagónicos, después de la aplicación de un biotratamiento en el que no se alcancen los niveles de hidrocarburos fijados por la legislación vigente.

\section{Bibliografía}

1. De la Rosa-Pérez D, Teutli-León MM, Ramirez-Islasn ME. Rev Int Contam Ambient. 2007;23:129-138.

2. Lindgren ER, Mattson ED, Kosak MW. Am Chem Soc Symp. 1994;554:33-50.

3. Wick L, Shi L, Harms H. Electrochim Acta. 2006;52:3441-3448.

4. Virkutyte J, Sillanpää M, Latostenmaa P. Sci Tot Environ. 2002;289:97121.

5. Pucci GN, Pucci OH. Rev Argent Microbiol. 2003;35:62-68.

6. Maini G, Sharman A. In: Bioremediation of Metal and Inorganic Compounds. Lesson A, Alleman B, editors. USA: Battelle Press; 1999. P. 127.

7. Marks R, Acar Y, Gale R. In: Remediation of Hazarous Waste Contaminated Soil. Wise D, Trantolo D, editors. New York: Marcel Dekker; 1994. P. 405.

8. Niqui-Arroyo J, Bueno-Montes M, Posada-Baquero R, Ortega-Calvo JJ. Environ Pollut. 2006;142:326-332.

9. Murillo-Rivera B, Labastida I, Barrón J, Oropeza-Guzman MT, González I, Teutli-Leon MMM. Electroch Acta. 2005;54:2119-2124

10. Wick L, Mattle P, Wattiau P, Harms H. Environ Sci Technol. 2004;38:4596-4602.

11. A.J. Acuña, O.H. Pucci, G.N. Pucci, Ecosistemas. 17 (2008) 85-93.

12. Trejo G. Experimentos en Microbiología del Suelo. México: Compañía Editorial Continental SA; 1981. P. 14.

13. Reasoner DL, Geldreich EE. Appl Environ Microbiol. 1985;49:1-7.

14. Xuejun C, Zhemin S, Yangming L, Shenshen Z, Bingxin J, Wenhua W. Soil Sci. 2006;171:638-647.

15. Gootaek L, Heeemyoung L, Sangmo L. Geosci J. 2006;10:85-89.

16. Thevanayagam S, Rishindran T. J Geotech Geoenviron Eng. 1998;124:330338.

17. Laursen S. Can Geotech J. 1997;43:664-671.

18. Shapiro AP, Probstein RF. Environ Sci Technol. 1993;27:283-291. 
19. Schmidt CA, Barbosa MC, Almeida MS. J Hazard Mater. 2007;143:655661.

20. Suni S, Romantschuk M. FEMS Microbiol Ecol. 2004;49:51-57.

21. Deflaun MF, Condee CW. J Hazard Mater. 1997;55:263-277.

22. Bayer ME, Sloyer JL. Gen Microbiol. 1990;136:867-874.

23. Da Rocha UN, Tótola MR, Pessoa DM, Araruna DT, Neves JCL, Borges AC. J Hazard Mater. 2009;61:485-491.

24. Lear G, Harbottle MJ, Van Der Gast CJ, Jackman SA, Knowles CJ, Sills G, Thompson IP. Soil Biol Biochem. 2004;36:1751-1760. 